\title{
UK Library and Information Science Research Matters
}

\section{By Dr Hazel Hall}

Centre for Social Informatics, School of Computing, Edinburgh Napier University, 10 Colinton Road, Edinburgh EH10 5DT

h.hall@napier.ac.uk

Telephone: +44 (0)131 455 2760; fax +44 1314552727

Library and Information Science Research Coalition, UK hazel.hall@lisresearch.org

Telephone: +44 (0)7 969 (0)7 8181

This is the manuscript of an article published in volume 33, issue 1 of Library and Information Science Research in January 2011. The full citation of the published version is:

Hall, H. (2011). UK library and information science research matters. Library and Information Science Research, 33(1), 89-91. (DOI 10.1016/j.lisr.2010.06.001.)

Full-text of the final published version can be accessed from Science Direct at http://www.sciencedirect.com/science/journal/07408188

\begin{abstract}
The Library and Information Science Research Coalition was formed in 2009 in response to a number of concerns related to library and information science research in the UK. In the first year of its implementation the Coalition has engaged in a number of activities to address these issues, in particular those related to the practitioner research gap, and efforts to build an evidence base on the value and impact of library and information services. The Coalition plans to extend its work into a second year with a number of new initiatives. The approach adopted is discussed with reference to the establishment of coalition governments.
\end{abstract}

\section{Introduction}

The term "coalition" has enjoyed a renewed prominence in everyday vocabulary in the UK since the outcome of the general election of May $6^{\text {th }}$ 2010. The UK coalition government - the first of its kind since 1945 - was, however, predated by another newly-formed coalition in the UK. The Library and Information Science (LIS) Research Coalition was established 14 months earlier to UK address UK LIS research matters. This paper discusses the formation of the LIS Research Coalition with reference to its goals, work to date, and future plans. 


\section{Coalition as a response to UK LIS research concerns}

In March 2009 the five main UK stakeholders in library and information science research signed a memorandum of understanding to establish the Library and Information Science Research Coalition. The signatories were:

1. the British Library (BL) - the national library of the UK (http://www.bl.uk);

2. the Chartered Institute of Library and Information Professionals (CILIP) - the main UK professional body for librarians and information scientists (http://www.cilip.org.uk);

3. the Joint Information Systems Committee (JISC) - a public-funded body that provides leadership in the innovative use of ICT to support education and research in further and higher education across the UK (http://www.jisc.ac.uk);

4. the Museums, Libraries and Archives Council (MLA) - the public body responsible for promoting best practice and innovation in museums, libraries and archives in the UK (http://www.mla.gov.uk);

5. the Research Information Network (RIN) - a UK policy unit that focuses on understanding and promoting the information needs of researchers (http://www.rin.ac.uk).

By joining forces in this way the five partners agreed to facilitate a coordinated and strategic approach to library and information science (LIS) research. This would be achieved by providing a formal structure to improve access to LIS research, and maximise its relevance and impact. The five founding members were joined in March 2010 by the Strategic Health Authority Library Leads (SHALL) group as an associate member. SHALL's mission is to support, work, plan and campaign for the excellence of health and social care through evidence-based practice and life-long learning by developing and providing high quality knowledge, information and library services.

The need for a formal organisation to coordinate a strategic approach to LIS research in the UK was initially identified in late 2006. It arose from a number of voiced concerns related to the state of UK LIS research. These included: the quality and reputation of LIS research; an over-reliance on a few favoured research approaches by the small numbers of LIS practitioners actually research-active; the isolation of LIS researchers, both from other members of their own community and researchers beyond it; low evidence of LIS research output influencing LIS practice; poor links between research output and efforts to forward the LIS research agenda; and a lack of an evidence base to demonstrate the value and impact of library and information services. Added to these is the gradual loss of power amongst the relatively small community of LIS researchers (in particular practitioner researchers) to influence LIS research strategy, as well a less favourable funding environment since the reallocation of responsibilities for LIS research from the British Library Research and Development Department in 1999 to a number of other bodies in succession, discussed elsewhere by Feather (2009), and Hall (2010). Over a period of two years, parties interested in addressing these concerns held consultations and workshops on possible structures for a new body. These included an invitation-only event in memory held at the British Library on 27 November 2006 in memory of Brian Perry, Director of the British Library's Research and Development Department, 1984-1995. Outcomes were published in a special issue of Library and Information Research in 2007 (volume 31, issue 97) and in a later paper by Kenna (2008). In August 2009 
- three years after the initial plans for a new body were first mooted - an Executive Secretary was appointed to work two days a week on implementing the Coalition's plans.

\section{Addressing the practitioner-research gap}

From the outset, it was recognised that the challenges that the LIS Research Coalition faces are wideranging. In an environment where there is some limited acknowledgement of the value of research, the barriers against its integration into everyday work as a professional relegates it to the status of a lowpriority, luxury activity. This is even the case where arguments for fostering research can be easily articulated - and supported - at a number of levels. For example, at the organisational level, access to research output informs practice and encourages strategic decisions on future services development. In addition, an understanding of a service's value and impact, as derived from in-house research, may be used to demonstrate accountability and justify future investment, both of which are particularly important in economic hard times when there is a strong imperative to drive down costs and/or access external funding. Equally, end-user relationships may be enhanced through improved engagement with patrons' perspectives and a closer understanding of their needs for particular services. Presenting the opportunity to staff to engage in research as part of their job role also has its advantages, not least because it involves their making a more personal connection with work. For example, job satisfaction may increase as individuals enjoy the intellectual stimulation offered by the challenges of undertaking research projects, and pride in work grows when service delivery is enhanced as a direct result of interventions based on research findings. In certain environments, visible research activity on the part of library and information services staff can serve to raise their professional standing amongst peers in other units. This applies, for instance, to academic librarians who undertake research in universities and colleges alongside faculty members working on their own projects. Ambitious staff also acknowledge that a research-active profile adds to both their reputation and resume, and serves as preparation for career progression into leadership roles.

From the perspective of the LIS profession at large, research is valuable to share good practice across service boundaries, and to raise the profile of the LIS profession as one that is evidence-based like others, such as medicine. Perhaps most important at this level is the potential for an evidence base to support the broad claims of LIS value. Library and information services support a number of constituencies, such as: individuals, for example in supporting education and social mobility; citizens and society, for example in enhancing local communities and contributing to culture and heritage; and specialist user groups, for example by delivering information services to business which, in turn, supports economic development. Thus conversation and debate around library and information services travels beyond the boundaries of the discipline, with a greater potential to create new knowledge and drive innovation in practice. In short, those who undertake research in the present are defining the professional future for their colleagues.

These arguments, however, often fade in the reality of the everyday working environment of potential LIS practitioner researchers. The time constraints of the practitioner role represent a particular issue. There is little space for research activity, even for reflecting on the work of others in the field by accessing the research literature. The idea of designing and implementing a research project, then 
working towards publication of its output, is simply out of the question when pressing services priorities take precedence in the working week. Any such ambitions are further impeded by organisational cultures that simply do not foster research engagement. For example, where a tradition of research has not yet been established, access to research sponsors or mentors who may provide guidance or serve as role models, is rare. In many cases practitioners lack confidence in their skills and experience as researchers, even when they may actually be reasonably well-qualified to execute projects. A further issue is access to external support for research initiatives, for example in navigating a literature that is found in a range of domains, knowing where to find funding and partners, or understanding the publishing environment so that reports of work are sensibly targeted.

\section{LIS Research Coalition achievements in year 1}

In the first year of its implementation, the LIS Research Coalition has channelled efforts to respond to the commonly cited reasons why the execution of research is a rare practitioner priority. These have included the creation of resources to save LIS researchers' time, advocacy to persuade services managers of the need to support research initiatives, and efforts to improve recognition of research knowledge within the profession. Plans have also been made for the development of online resources and running of events to extend the repertoire of research approaches in LIS. In short, the Coalition aims to be a focus for the external support of LIS research in the UK.

Progress so far can be evaluated by considering five specific goals of the LIS Research Coalition:

1. to bring together information about LIS research opportunities and results;

2. to encourage dialogue between research funders;

3. to promote LIS practitioner research and the translation of research outcomes into practice;

4. to articulate a strategic approach to LIS research;

5. to promote the development of research capacity in LIS.

The Coalition web site (http://lisresearch.org) has been designed to respond to the first goal. Here, for example, are links to funding bodies and conferences of relevance to LIS research. The Coalition also uses Twitter (@LISResearch) to disseminate LIS research news, covering topics such as: funding opportunities; studentships; jobs; invitations to join committees, take part in consultations and contribute to the research projects of others; new publications including research reports, monographs and journal issues; training events; calls for papers; awards; and forthcoming conferences. At the time of writing this article (May 2010), 556 people were following the Coalition's Twitter feed. As far as promoting LIS practitioner research is concerned, the Coalition has prioritised strong advocacy through face to face engagement. In a number of formal presentations at professional events and conferences Hazel Hall has called on services managers to encourage practitioner research and its dissemination, and to promote the application of research findings in the workplace. In tandem, the main messages have been spread across various media with print, online and podcast news reports of the Coalition's activities and contributions to national and international peer-reviewed journals and conferences (Hall, 2010; Hall \& Brazier, 2010), as well as coverage in the mainstream media, including the national press, such as Times Higher Education. Dialogue between research funders is achieved the meetings of the 
Board of Directors of the LIS Research Coalition, and at Coalition events that representatives of funding bodies attend, such as the conference at the British Library on $28^{\text {th }}$ June 2010

(http://lisresearch.org/conference-2010. Work towards influencing research strategy has included contributing to the consultation on the UK Research Excellence Framework proposals published in late 2009 (Higher Education Funding Council for England, 2009).

\section{Building on LIS Research Coalition achievements of year 1}

As the second year approaches, the Coalition is turning its attention to future priorities. For the LIS research community at large, the intention is to build on the infrastructure established to date to ensure that as wide a range of LIS professionals can be supported in their research efforts. Extensions to current provision may include, for example: an enlarged range of research support services accessible from the Coalition web site: a practitioner researcher starter "kit" of research-related web links; an online listing of live research awards; wiki-based resources that facilitate networking for the purposes of learning about the research of others and establishing research mentor relationships. A series of research workshops is also planned. Such tools and events, designed to support all stages of the research process from identifying research questions to disseminating output, will build on the work of 2009/10 in addressing two of the main features of the practitioner-researcher gap: limited time for research and a perceived lack of research skills. Time savings should give LIS researchers greater scope to focus on conducting and publishing research, not least thanks to savings on effort dedicated to activities such as identifying possible methodological approaches for individual pieces of work.

To meet the ambition of proposals for its second year the LIS Research Coalition relies on its membership. Crucial to the Coalition's future are (1) sustained funding through membership fees, and (2) the provision of strategic direction for the body through the work of the LIS Research Coalition Board of Directors. Thus in its second year the Coalition will make further invitations to key LIS research stakeholders to invest in - and influence - the UK LIS research agenda, so that an evidence base of robust research in LIS can be developed in the UK. This can then be used to underpin future services developments, demonstrate the value and impact of library and information services, and contribute to future UK LIS research strategy.

\section{Conclusion}

UK coalition governments have traditionally come into being at a time of national crisis. While it would be an exaggeration to say that by 2006 UK LIS research had reached a crisis point in its history, it was recognised that failure to act on the situation that existed at that time posed significant risks. There was a clear set of arguments for the implementation of the LIS Research Coalition, particularly in respect of the practitioner research gap, and the need for a strong evidence base to demonstrate the value and impact of library and information services. The relevance of the challenges identified to the broad range of stakeholders - from those who commission research to its consumers - has led to collective action. As a result, issues that would have been difficult for a single body to address, are now being identified and tackled with the support of the wider community. In the same way that coalition governments are often regarded as more democratic than single party administrations, this approach opens up the agenda to 
all members of the UK LIS profession (especially since one of the Coalition members is the leading UK professional body for library and information professionals), and there is greater potential for shared consensus on action to prove that library and information science research does, indeed, matter.

\section{Acknowledgements}

The author thanks the members of the Board of Directors of the Library and Information Science Research Coalition for their comments on the draft of this article.

\section{References}

Feather, J. (2009). LIS research in the United Kingdom: reflections and prospects. Journal of Library and Information Science. 41(3), 173-181.

Hall, H. (2010). Promoting the priorities of practitioner research engagement. Journal of Library and Information Science. 42(2), 83-88.

Hall, H. \& Brazier, C. (2010). Implementing a co-ordinated and strategic approach to Library and Information Science research: the work of the UK Library and Information Science Research Coalition. In Proceedings of the 76th International Federation of Library Associations General Conference and Assembly, Gothenburg, Sweden , August 10-15 2010.

Higher Education Funding Council for England (2009). Research Excellence Framework: Second Consultation on the Assessment and Funding of Research. Bristol: HEFCE.

Kenna, S. (2008). Towards a coalition for research in library, archive and information science. Library and Information Research, 32(100), 3-9. 